This item was submitted to Loughborough's Research Repository by the author.

Items in Figshare are protected by copyright, with all rights reserved, unless otherwise indicated.

\title{
Switch the channel: using cultural codes for designing and positioning sustainable products and services for mainstream audiences
}

\section{PLEASE CITE THE PUBLISHED VERSION}

http://dx.doi.org/10.1016/j.jclepro.2015.09.130

\section{PUBLISHER}

(C) Elsevier

VERSION

AM (Accepted Manuscript)

\section{PUBLISHER STATEMENT}

This work is made available according to the conditions of the Creative Commons Attribution-NonCommercialNoDerivatives 4.0 International (CC BY-NC-ND 4.0) licence. Full details of this licence are available at: https://creativecommons.org/licenses/by-nc-nd/4.0/

\section{LICENCE}

CC BY-NC-ND 4.0

\section{REPOSITORY RECORD}

Santamaria, Laura, Carolina Escobar-Tello, and Tracy Ross. 2015. "Switch the Channel: Using Cultural Codes for Designing and Positioning Sustainable Products and Services for Mainstream Audiences". Loughborough University. https://hdl.handle.net/2134/19614. 


\section{Switch the channel: using cultural codes for designing and positioning sustainable products and services for mainstream audiences}

Article in Press, Journal of Cleaner Production, 10/ 2015. http://dx.doi.org/10.1016/j.jclepro.2015.09.130

Corresponding Author: Laura SANTAMARIA, l.santamaria@lboro.ac.uk

Co-authors: Carolina ESCOBAR-TELLO, M.C.Escobar-Tello@lboro.ac.uk; Tracy ROSS, T.Ross@lboro.ac.uk

Loughborough Design School, Loughborough University, Epinal Way, Loughborough LE11 3TU, United Kingdom

Abstract:

An important step towards achieving sustainability is to encourage a wide uptake of more resource-efficient consumption patterns by the mainstream of society. In this paper, it is argued that by paying more attention to the elaboration of meaning - or symbolic value - designers can develop innovations that are more appealing and relevant to a wider range of potential users, especially by positioning sustainable products, services, and systems as aspirational choices that lead the user to improved well-being and happiness. The theoretical proposition is explored in the context of sustainable Product Service Systems (sustainable PSS), analysing the opportunities they pose for systemic disruption as radical innovations, and proposing a design framework for tackling the cultural barriers for their mainstream adoption. Based on the theoretical propositions, an initial methodological framework for the integration of semiotic and cultural analysis methods to the design process is discussed, in order to better support designers in identify the cultural codes that can make sustainable PSS innovations more relevant and desirable in their socio-cultural context. In exploring the potential of semiotics and cultural analysis methods as a strategy to improve the value proposition of sustainable innovations, we offer a new perspective for understanding the symbolic aspects of consumption as social signifier, and highlight the opportunities this opens for sustainable design to influence societal transformation.

Keywords: sustainable consumption; PSS design; semiotics; aesthetics; consumer behavior; well-being 


\section{Introduction}

It is now widely acknowledged that a transition to more sustainable lifestyles is required to secure the subsistence but also the well-being and human development of future generations (Brown and Vergragt, 2015; Jackson and Victor, 2013; Layard, 2011). Although awareness of environmental challenges is widespread, actual reduction in consumption levels is well under the required targets (Mont et al., 2014). Despite the ever-increasing proliferation of sustainable innovations, the adoption of more sustainable lifestyles by mainstream society is disappointingly low (Nelson, 2008) and needs to be accelerated.

Design has long acknowledged the need to address social and environmental concerns (Manzini, 1999; Melles et al., 2011; Papanek, 1985). But while technological improvements in resource efficiency have helped alleviate environmental impact (i.e. eco design, cradle to cradle), strategies for disrupting the dominant, unsustainable consumption patterns lie within the next challenges (Manzini and Vezzoli, 2003; Manzini, 2014; Mylan, 2014; Vergragt et al., 2014) as the diffusion and adoption of sustainable design innovations at a mainstream level is still niche (Mont and Plepys, 2008).

Barriers to the adoption of more sustainable consumption patterns have been attributed to entrenched habits, resistance to change, value-action gap, pricing, inconvenience, lack of availability and regulation (Kollmuss and Agyeman, 2002; McKenzie-Mohr, 2013; Mont and Plepys, 2008). However, in a free market economy, such established norms and status quo arrangements are often disrupted by the introduction of radical innovations, i.e. new propositions offering better value (be it tangible or intangible). It is self-evident that cultures are in constant flux, with new technological advances (e.g. smartphones) and practices (e.g. healthy diet) widely and happily adopted at a global scale all the time (Norman and Verganti, 2014), when users judge them to add value to their lives, in material or psychological terms. Historically, brands and products have challenged established meanings and practices of entire categories, and with it transformed cultural practices and behaviours. In this, design has played a key role, leveraging technologies, legitimising values and social practices and reconciling dilemmas through its representations (du Gay et al., 2013; Maguire and Matthews, 2012).

Consumption practices, cultural reproduction and identity are complexly interlinked aspects of socio-economic paradigms. Changing user's existing habits, beliefs and activities and creating new ones for sustainability requires a deep cultural transformation- a 'transition of minds' rather than purely technological innovations (Lakoff, 2010), where what is normally considered of value is redefined. Increasing demand for sustainable innovations is key to push the legislative and regulatory agendas. As public interest in the redefinition of 'the good life' rises and great social changes gain momentum (Brown and Vergragt, 2015), designers are challenged to support systemic change by developing sustainable products and services that improve current environmental conditions, but also the users' quality of life by fulfilling their expectations, personal aspirations and social identification needs (Gilbert-Jones, 2013).

In this, sustainable Product Service Systems (PSS), a combination of products and services, have been highlighted as a strategy with great potential for systemic change (Manzini and Vezzoli, 2003). Sustainable PSS are defined as 'an offer model providing an integrated mix of products and services that are together able to fulfil a particular customer demand (to deliver a 'unit of satisfaction'), based on innovative interactions between the stakeholders of the value production system (satisfaction system), where the economic and competitive interest of the providers continuously seeks environmentally and socio-ethically beneficial new solutions' (Vezzoli et al., 2014).

These innovations represent a promising approach for transitioning 'minds' towards sustainable consumption that fits the emerging dematerialised economy and as such, can allow for new associations of value. Beyond the advantages of lowering resource consumption by decoupling the creation of value and satisfaction from product ownership to the consumption of services, sustainable PSS open up an exciting territory to explore new consumption patterns, where value and identity are constructed around practices and experiences rather than products and possessions (Vezzoli et al., 2014). Sustainable PSS represent a fertile ground for socio-cultural disruption in that:

- Their emphasis in satisfaction through intangible offerings allows for the repositioning of perceived value from physical objects to experiences and relationships

- $\quad$ Configuration of processes and practices allows for the internalisation of new habits and routines that are more sustainable

- $\quad$ They contribute to a paradigm shift where wealth is perceived as access rather than ownership

However, as radical innovations, they also face considerable barriers for introduction and acceptance. In this, sustainable PSS are no different from other product or service innovations, as Norman and Verganti (2014) argue, the most common reason radical innovations fail is that society is not ready for them.

Thus, there is still a great need for research regarding the relation between consumers and sustainable innovations (Mont and Plepys, 2008; Rexfelt and Ornäs, 2009; Vezzoli et al., 2015). Although the urgency to understand users' expectations, especially users within their social contexts and communities has been recognised (Vezzoli et al., 2015), the elaboration of new theories to support PSS designers in better understanding the social rules at play in the context of the innovation, and the symbolic aspects of consumption has been lacking. Equally, development of new knowledge to support sustainable PSS designers is needed (Vezzoli et al., 2015). 
Interdisciplinary research and collaboration are necessary to elaborate new strategies, as highlighted in the call for papers for this special issue. In this article, we explore the potential that semiotics and cultural analysis methods (widely used in consumerist propositions) offer as a strategy to improve the value proposition of sustainable innovations. We intend to contribute particularly to the diffusion and uptake of sustainable PSS field of research by offering a new perspective for understanding consumption as a social signifier, and highlighting the opportunities this opens for designers to influence societal transformation. We argue that by paying more attention to the elaboration of meaning - or symbolic value - designers can develop innovations that are more appealing and relevant to a wider range of potential users. It is proposed that strategically framing innovations using contextually appropriate and aspirational cultural associations or 'codes' during the design process can result in sustainable innovations that are more in tune with their context. Semiotic and cultural analysis methods can aid in identifying favourable codes and inform the design and innovation's value proposition.

The following sections explore these concepts in the context of sustainable PSS specifically; analysing the opportunities they pose for systemic disruption as radical innovations, and propose an initial theory for tackling the cultural barriers for their wider adoption, in order to understand how these methods can empower design in shifting dominant associations of value.

\section{Semiotics and cultural codes}

Cultural codes are socially agreed conventions and practices familiar to the members of a culture. They play a big role in the construction of social realities, such as class differentiation and identity by reflecting certain values, attitudes, beliefs, assumptions and practices (Nöth, 1990). An understanding of codes enables us to deal with the symbolic aspects of consumption and what these 'look like' as represented in material terms (for example, in a western context, an established aesthetic code for female is 'pink', and male is 'blue').

Codes are a fundamental object of study in semiotics. When studying cultural practices, semioticians treat as 'signs' any objects or actions which have meaning to members of the cultural group, seeking to identify the rules or conventions of the codes which underlie the production of meanings within that culture (Nöth, 1990).

Ceschin et al., (2014) and Vezzoli et al., (2015) and have highlighted the role that semiotics and aesthetics 'could and should' play in enhancing specific inner qualities of sustainable PSS, so that 'they are perceived as better than the existing and unsustainable panorama of artefacts' (Ceschin et al., 2014, p.216). Markussen (2013) has also acknowledged the value of design aesthetics for opening up possibilities with users. He progresses the notion of 'disruptive aesthetics' as a sphere for design activism, recognising that design has both 'a political potential to disrupt or subvert existing systems of power and authority, thereby raising critical awareness of ways of living, working, and consuming', but also the ability to 'to open up the relation between people's behaviour and emotions' (p.39). Mandoki (2007, p. xvii) clarifies that although aesthetics is necessarily linked to semiotics, from semiotics we obtain meaning and sense (coherence), from aesthetics openness and sensitivity (adherence). This aesthetic-semiotic approach extends the scope of design beyond functionality and usability features to encompass the elaboration of symbolic features - the meanings that these innovations are intended to carry for the user (Ceschin et al., 2014). Semiotic methods allow for the strategic selection of 'cultural codes', offering the opportunity to construct favourable meanings and appeal for sustainable PSS innovations, rooting the innovation in its social context so that it can be more easily understood and valued by potential users.

Semiotics, traditionally defined, is 'the study of signs and their meanings', but nowadays is considered a discipline that deals with the study of the representations that enable human cognition (meaning making) and communication. Contemporary social semiotics studies signs and codes as part of semiotic systems or discourses that are socially constituted and treated as social practices and concerned not only with communication but also with the construction and maintenance of reality (Denzin and Lincoln, 2003). This approach also deals with ideological complexes, the relationships and inequalities in the distribution of power, wealth and goods in capitalist societies (Castells, 2013; Hodge and Kress, 1988).

Semiotics became a major approach to cultural studies in the late 1960s, with Roland Barthes, who declared that the discipline 'aims to take in any system of signs, whatever their substance and limits; images, gestures, musical sounds, objects, and the complex associations of all of these, which form the content of ritual, convention or public entertainment: these constitute, if not languages, at least systems of signification' (Barthes 1967, p.9).

As signs, goods are free to take on any association or meaning as a play of 'signifiers' or cultural social markers (Baudrillard, 1988). Through advertising, display, packaging, branding, product design and other forms of mediation, 'commodity goods' - products and services - are conferred with myths (or symbolic associations), which appear to be 'natural' to it (Barthes, 1967). Hence, semiotic methods are useful for 'decoding' these myths and mapping meanings in a cultural landscape, making explicit how they are constructed and represented (Julier, 2013).

These theories inspired the application of semiotics to consumer insight and marketing, now well-established as a powerful alternative methodology to conventional market research (Harvey and Evans, 2001; Maggio-Muller and Evans, 2008; Oswald, 2015, 2012). Marketing semiotics experienced a sharp rise in influence with the growth of brand strategy 
and management since the 1990s, and particularly with the rise of megabrands requiring cross-cultural and global communication platforms (Evans and Shivakumar, 2010).

Some benefits of marketing semiotics research include the ability to create disruptive innovation by identifying emerging meanings and breaking the current normative codes; and foresight in identifying patterns of change in culture and anticipate trends. Semiotic research is employed as a strategy for mainstream diffusion of innovations, by identify the themes and codes which occur with sufficient frequency to have a likelihood of transitioning into the dominant or mainstream culture (Evans, 2014).

In contrast to traditional market research, which gains insights mostly by consulting users directly (e.g. by means of interviews, focus groups and questionnaires), marketing semiotics draws insights from the study of discourses expressed via popular culture representations (media, advertising, music, film, etc.), by employing semiotic, cultural analysis and ethnographic methods. Some examples of the methods employed are summarised in Error! Reference source not found.

\begin{tabular}{|c|c|c|}
\hline Type & Description & Function \\
\hline Paradigms & $\begin{array}{l}\text { A set of related oppositions } \\
\text { (e.g. clean/dirty) }\end{array}$ & $\begin{array}{c}\text { It breaks cultural and category codes into two opposite sets. } \\
\text { Normally a good place to start to the code mapping process, see } \\
\text { opportunities for innovation and creativity and to resolve trade-offs } \\
\text { and cultural contradictions. }\end{array}$ \\
\hline $\begin{array}{l}\text { Code Mapping } \\
\text { (context) }\end{array}$ & $\begin{array}{l}\text { A snapshot of the cultural } \\
\text { landscape frozen in time, and } \\
\text { the active codes present at } \\
\text { that particular time. }\end{array}$ & $\begin{array}{l}\text { Searches for key metaphors and themes present in the category by } \\
\text { dividing it up. } \\
\text { Good for locating developing themes, and cross fertilisation with } \\
\text { themes from other related categories. }\end{array}$ \\
\hline $\begin{array}{l}\text { Code Mapping } \\
\text { RDE (trajectories) }\end{array}$ & $\begin{array}{l}\text { Residual, dominant and } \\
\text { emergent codes. }\end{array}$ & $\begin{array}{l}\text { Maps the cultural shift of values, meanings and cultural codes } \\
\text { diachronically. Useful for observing how cultures change, new ways } \\
\text { of thinking and potential mainstream future trends. }\end{array}$ \\
\hline Semiotic Square & $\begin{array}{c}\text { Paired concepts analysis } \\
\text { based Jakobson's distinction } \\
\text { between contradiction and } \\
\text { contrariety }\end{array}$ & $\begin{array}{l}\text { Useful for accessing deep structures informing the communication } \\
\text { and perception of meaning - i.e. the underlying cultural 'software' - } \\
\text { and connections with structures of power and logic. }\end{array}$ \\
\hline Cultural Archetypes & $\begin{array}{l}\text { Rooted symbols and cultural } \\
\text { archetypes such as gold, } \\
\text { America, home, work, family, } \\
\text { etc. Received wisdom, 'what } \\
\text { everyone knows' and goes } \\
\text { without saying }\end{array}$ & $\begin{array}{c}\text { Useful for building narratives and associations with deep-rooted } \\
\text { cultural values and traditions. Normally used in storytelling material, } \\
\text { film, novels and popular culture. }\end{array}$ \\
\hline Myth & $\begin{array}{l}\text { Express and serve to organise } \\
\text { shared ways of } \\
\text { conceptualising something } \\
\text { within a culture }\end{array}$ & $\begin{array}{l}\text { Serve as process of naturalisations - i.e. to make dominant and } \\
\text { historical cultural values seem 'normal', 'natural, and 'common } \\
\text { sense'. They can serve to hide the ideological function of signs and } \\
\text { codes because they appear as self-evident truths. }\end{array}$ \\
\hline
\end{tabular}

Table 1 - Some of the semiotic operations that are applied to market research

The semiotic approach to marketing concentrates on uncovering 'naturalised' meanings which users are often unable to articulate, because these operate largely at subconscious level (Rapaille, 2007; Oswald, 2012). While many marketing and market research methods try to understand the user's preferences in isolation, semiotic methods acknowledge that many of the individual's beliefs, preferences and behaviours correspond to 'implicit' socially agreed rules, expressed through social signifiers to mark social status and so form 'in' and 'out' groups. Figure 1 illustrates the typical 'cultural landscape' or cultural context that is normally analysed to uncover such implicit rules and their corresponding signifiers or 'codes' of representation.

Evans (2014) reports a set of 'simplified semiotic tools' that are directed to improve brand communications, position new brands, products and services in the 'mainstream cultural landscape' and also for radical product innovation (innovation that is not based on existing customer needs). His process comprises two main stages: Decoding (analysis) and Recoding (incorporating findings into design and communications). The steps are illustrated in Figure 2. 


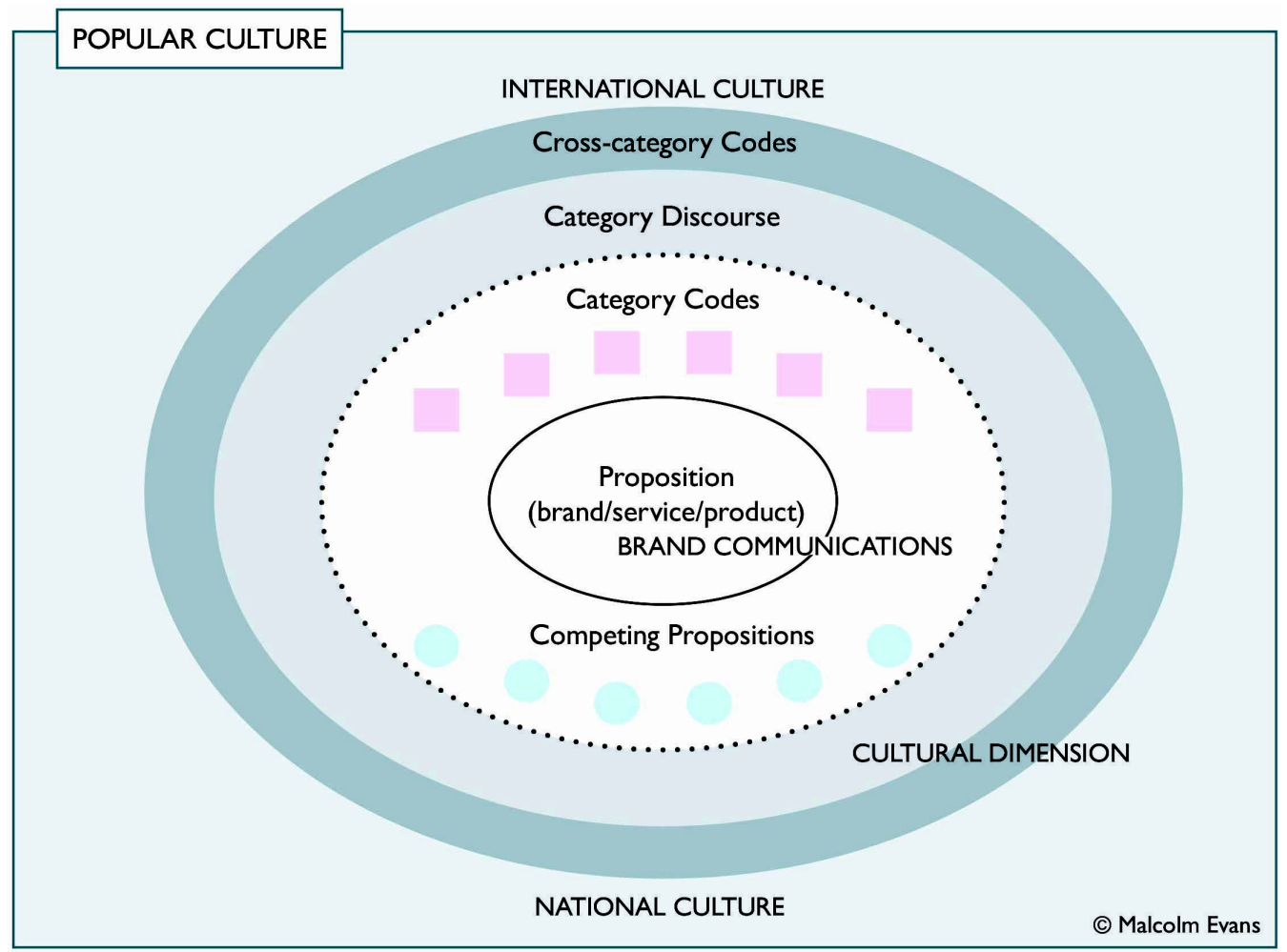

Figure 1 - Cultural landscape of semiotic analysis for market research purposes (Evans, 2014). Reproduced with the author's permission.

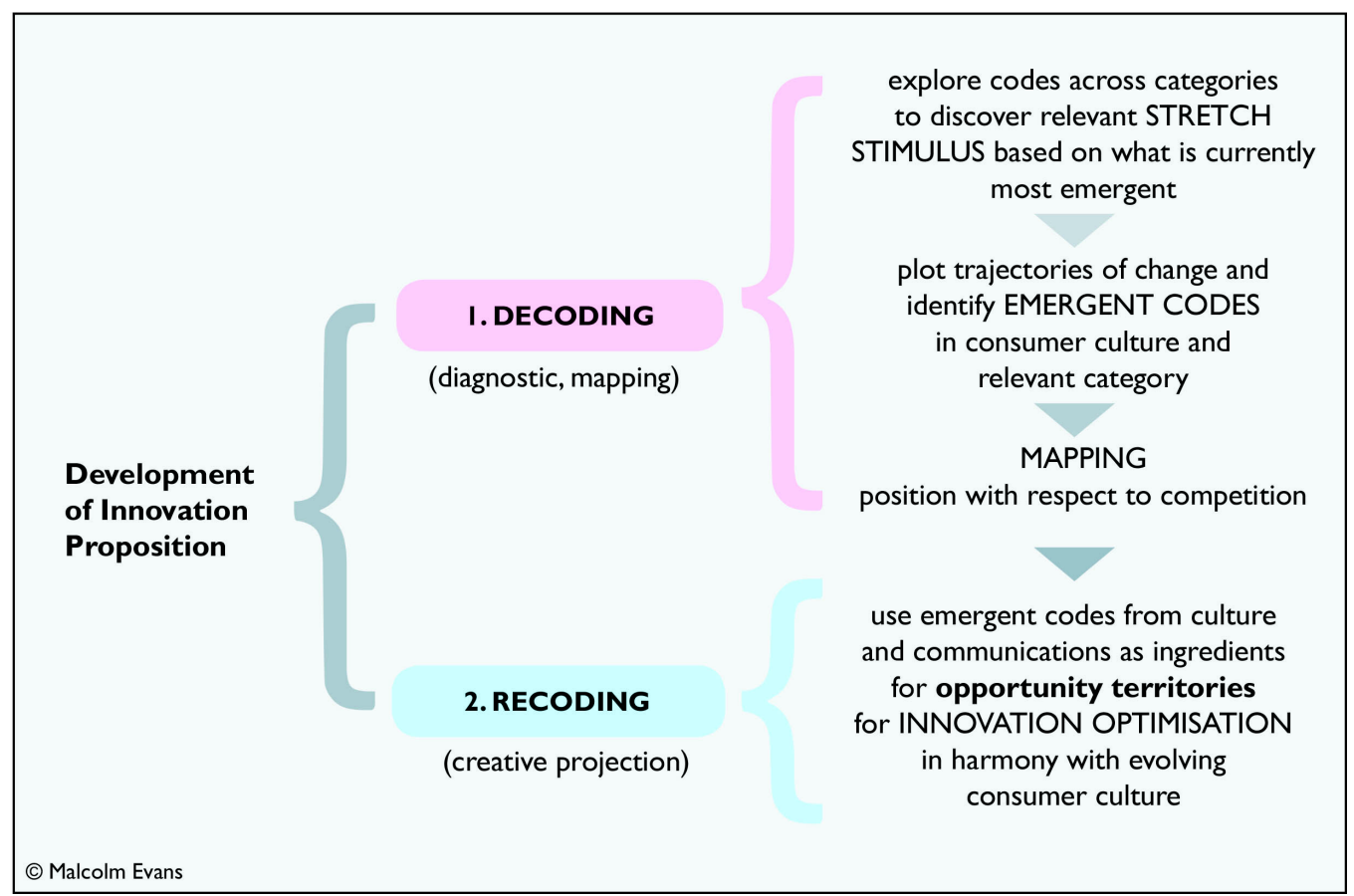

Figure 2 - Semiotic process adapted from Evans (2014). Reproduced with the author's permission.

Applied semiotic methodological tools draw from structural and post-structuralist semiotics, and have been enriched by adjacent academic areas such as cultural studies (Evans and Shivakumar, 2010) - for example, through the application of Residual, Dominant and Emergent cultural analysis of codes (Williams, 1977) for understanding (and helping create) cultural trends and to develop leading brand cultural equities and communication strategies.

Oswald $(2012,2015)$ has applied similar semiotics methods for retail and packaging design, and hold that 'cautious marketers develop design strategy from a thorough understanding of the codes structuring the perception of value in a given market or product category.' Cultural anthropologist and marketing researcher G. Clotaire Rapaille developed a 
method based on a mix of code and psychoanalysis theories and has worked commercially for over three decades, providing multinational corporations with strategic cultural insights for introducing brands and products successfully across cultures (Rapaille, 2007).

All the approaches mentioned above employ semiotic, cultural analysis and cognitive-linguistic knowledge, and benefit from empirically tested outcomes applied in commercial contexts. Therefore, if appropriately adapted and incorporated into existing design approaches and methods, they could offer great potential to inform the design and innovation stages of sustainable products and services in terms of enhancing mainstream appeal and adoption. However, as these methods have been executed by professional semioticians and market researchers working in top-down organisation settings, their implementation to empower bottom-up systemic innovation as well as their integration to the design process still needs to be empirically investigated (Ceschin et al., 2014).

\section{The role of design in shifting cultural associations of value}

The socio-cultural meanings of goods have been well documented in marketing management (Oswald \& Mick, 2006), design (Crilly et al., 2008; Julier, 2013; Shove et al., 2007; Verganti, 2008) and material culture (Henare et al., 2007) literatures. There is a general consensus that meanings flow among cultural categories and consumer goods via cultural intermediaries, including designers, marketers and consumers (Maguire and Matthews, 2012). In a global consumer culture, brands establish a symbolic exchange through the meanings consumers attach to the brand name, logo, and product category. This symbolic meaning (desirability, identity and legitimacy) is not just a value added to the financial value of goods, but has material impact on financial markets themselves (Oswald, 2015).

Designers construct symbolic value by 'framing' artefacts - i.e. they create narratives that associate goods, services and brands with certain values, attributing identity and meanings to them by recalling existing cultural codes (du Gay et al., 2013, p. 9). However, these meanings are not fixed: contemporary technological, environmental and socio-cultural shifts disrupt the extant codes, values and relationships that constitute them. Such cultural reconfigurations can be signified via design output that activates, reflects or accelerates them (Fuad-Luke, 2009). Thus, from watches to game consoles, design has leveraged new technologies and shifting cultural values to play an essential and powerful role in redefining the meaning of specific categories (Verganti, 2008).

Designers as 'cultural intermediaries' (Negus, 2002) are 'taste creators' (Bourdieu, 2010) and play a central role in the production of symbolic value through all designed artefacts, and therefore impact upon cultural values, beliefs and practices. The Circuit of Culture (du Gay et al., 2013) considers the central mediation role of design in cultural reproduction, identifying five major cultural processes: Representation, Identity, Production, Consumption and Regulation. Design's cultural mediation through the five 'circle of culture' operations is explored in Figure 3.

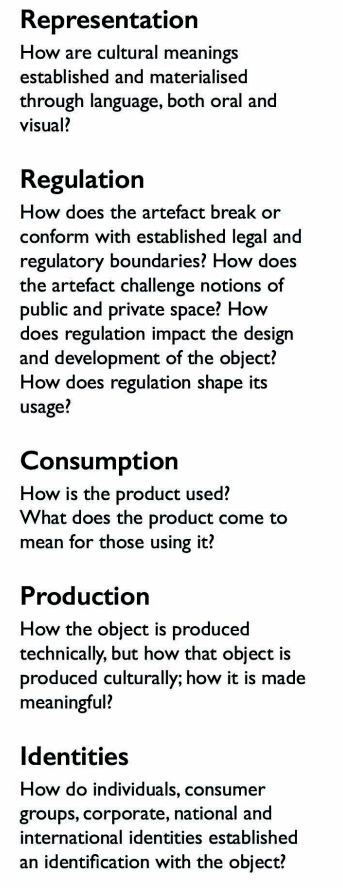

Representation

established and materialise

through language, both oral and

visual?

ate space? How

does regulation impact the design

and development of the object?

usage?

\section{Consumption}

How is the product used?

mean for those using it?

Production

How the object is produced

technically, but how that object is

meaningful?

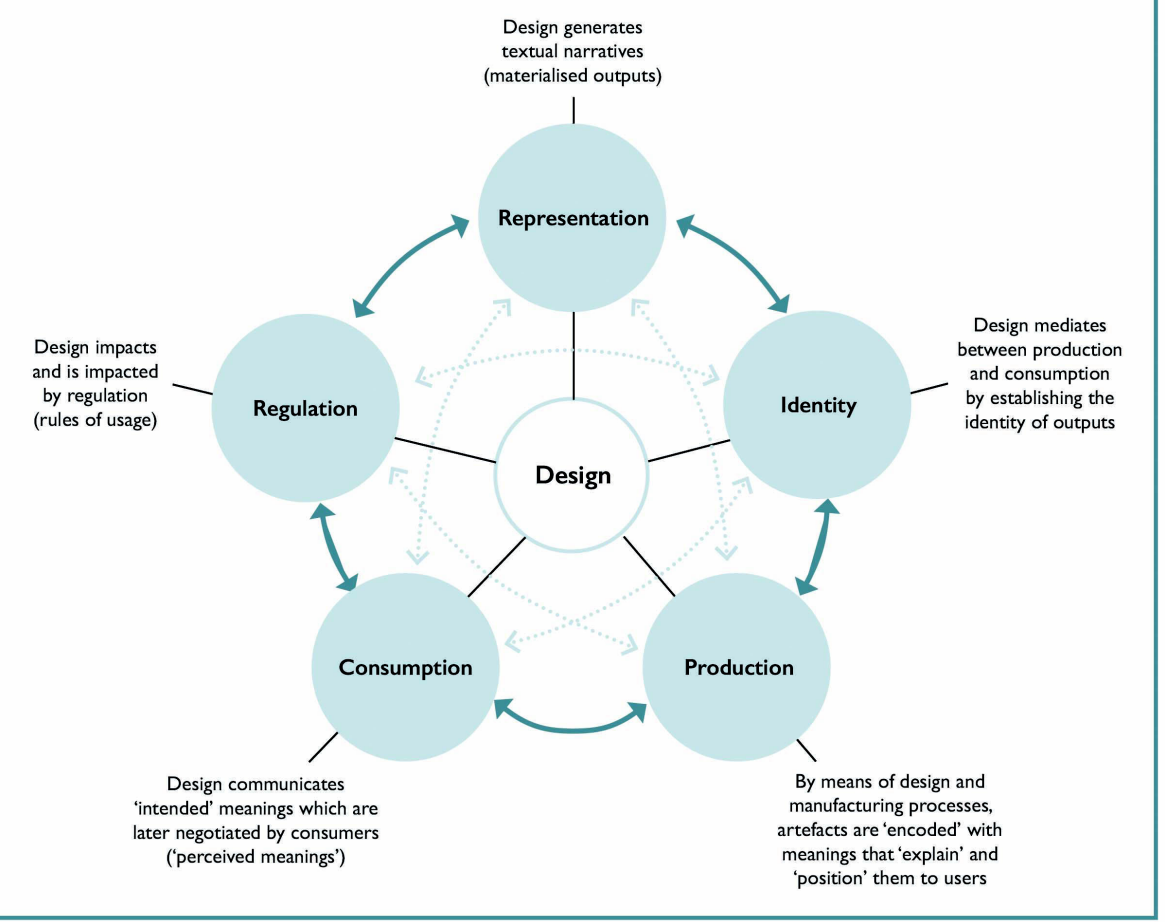

Figure 3 - The Circuit of Culture, adapted from du Gay et al. (2013) 
Consumption and production inform social identities, the way that artefacts are represented and their systems of regulation (rules of use, practices, legislation). Meanings are constantly transformed and rewritten by both producing agents (designers, marketers and distributors) and their consumers (Julier, 2013). Therefore, design artefacts are affected by socio-economic settings, but also effect the legitimation of values, practices and identity.

Due to its central role in the economic paradigm, it is impossible for design to remain neutral of influence with its output. Cultural intermediaries impact 'on the formation of value for particular products or practices' and 'upon notions of what, and thereby who, is legitimate, desirable and worthy, and thus by definition what and who is not' (Maguire \& Matthews, 2012, p. 552). Therefore, design bears certain responsibilities as well as privileges in relation to consumption practices and cultural ideals of value. As design affects and effects other people's orientation towards certain goods as legitimate, worthy and desirable, it can play a substantial role in helping to 'turn the tide' of consumerist culture, shifting orientation and legitimising the values that underpin more sustainable lifestyles by creating desirable sustainable goods and services.

Since design artefacts inevitably embody and reinforce values, it is important to pay close attention at what kind of values design should seek to strategically promote and legitimise in order to accelerate a transition towards human flourishing and sustainability (Ehrenfeld, 2013).

Values represent our guiding principles: our broadest motivations, influencing the attitudes we hold and how we act (Schwartz et al., 2012). It has been well documented that people's decisions are driven importantly by the values they hold - frequently unconsciously, and sometimes to the virtual exclusion of a rational assessment of the facts (Kahneman, 2012; Tversky and Kahneman, 1981). Values can be divided into two clusters: intrinsic or self-transcendent values (community, relationships, affiliation, self-development), considered to be innate and universal needs and essential for an individual's psychological health (Grouzet et al., 2005) and extrinsic or self-enhancing values (financial success, material wealth, power). Interdisciplinary research has evidenced the role of values in influencing consumer behaviour (Shaw et al., 2004) and engagement with environmental issues (Corner et al., 2014). Extrinsic values are associated with a poor sense of well-being and decreased pro-social and environmental attitudes, while intrinsic values are associated with a higher sense of well-being and increased pro-social and environmental attitudes. We live happier and more sustainable lifestyles when our goals and aspirations are driven by intrinsic values (Karp, 1996; Kasser et al., 2013; Schmuck et al., 1999).

Therefore, design that seeks to engage as an agent of cultural transformation (Julier, 2006) towards sustainability and well-being, must play an active role in legitimising intrinsic, and not extrinsic values.

\section{The concept of sustainable lifestyles in consumer culture}

All consumption is intrinsically a cultural process (Slater, 1999). As such, lifestyles reflect a particular worldview and its associated values. As previously discussed, values are represented or materialised through a set of particular cultural practices, discourses and aesthetics (cultural codes).

The culture of consumerism - which values consuming over doing, being or producing - is therefore, a unique and specific mode of cultural reproduction developed in the west over the course of modernity (Slater, 1999). This model dominates modern lifestyles in high-income countries and is based on the principles of a 'free market economy' of 'choice', promoting consumption as a way to freedom, well-being and happiness. In 1955, anthropologist and marketer, Victor Lebow introduced a vision for a 'consumer society' in which he laid the foundations of modern lifestyles values: 'Our enormously productive economy demands that we make consumption our way of life, that we convert the buying and use of goods into rituals, that we seek our spiritual satisfactions, our ego satisfactions, in consumption. The measure of social status, of social acceptance, of prestige, is now to be found in our consumptive patterns. The very meaning and significance of our lives today expressed in consumptive terms.' (Lebow, 1955, p.3)

Today, practices of consumption have been transformed from a means to meeting needs to a process for construction of personal identity (Belk, 2004), with citizens of affluent countries increasingly seeking a sense of self from consumption instead of their workplace, class or community (Hamilton, 2010). In this, Hamilton argues that 'the market rules less by material or political compulsion and more by consent' (ibid. p.573) due to the widespread popular belief that to find happiness one must be able to acquire more and have endless choice. The power of the market economy resides in this ideological strategy (Hamilton, 2010).

However, as a large body of evidence from happiness and well-being studies confirms, increasing consumption does not secure people's well-being and happiness, but in fact, it undermines them. Beyond environmental damage and resource depletion, its consequences are ever-increasing inequality, economic indebtedness, instability, conflict and decreased happiness and well-being (Kasser et al., 2013; Wilkinson and Pickett, 2009). Evidence also shows that above a certain threshold, increasing acquisitive power does not result in increased sense of happiness and life satisfaction (Kahneman and Krueger, 2006). When consumption becomes a substitute for lack of meaning and belonging, consumers lapse into a permanent state of unfulfilled psychological and social need (Belk, 2004; Hamilton, 2010; Kasser, 2002; Kasser et al., 2013). 
But, as most people in developed countries today seek 'proxy' identities by means of commodity consumption (Belk, 2004), in Hamilton's view 'environmental appeals to change consumption behaviour implicitly ask people not merely to change their behaviour but to change their sense of personal identity.' This can be perceived as threatening and produce indifference and dismissal (Hamilton, 2010). Consequently, alternatives proposed by sustainable consumption models, in its present form, are failing to mobilise most (Akenji, 2014; Hamilton, 2010).

\subsection{Consumerism lifestyles vs. the sustainable lifestyle proposition}

Building on current social arrangements, the concept of sustainable lifestyles proposes that in order to reduce one's carbon footprint, one should 'restrain' consumption within acceptable limits. To this end, alternative systems of provision are offered to the public under the umbrella category of 'sustainable', 'green' or' eco' products and services. Most of these are currently introduced via the marketplace and compete against other options, and at present, these propositions are not readily appealing to the many, but the few (Akenji, 2014; Mont and Plepys, 2008). It is therefore appropriate to assess how sustainable lifestyle propositions are (re)presented in culture, in comparison with what the dominant consumerism proposition is offering.

Personal Benefits - For a long time the sustainability discourse has assumed that highlighting the environmental benefits of sustainable offerings would be compelling enough for people to prefer these choices. But the growing societal concern with environmental issues has not directly translated into higher demand for sustainable offerings (McKenzieMohr, 2013). For example, sales of green products in the U.S. represent well under $1 \%$ in most categories (Makower, 2013).

In a culture on consumption people quite happily and often adopt new practices, services and products on the basis that these add value to their lives in material or psychological terms. Framing the offer to switch to sustainability around the environment benefits translates into the 'environment first'. Far from being presented as a personal gain, the offering generates action by guilt, or is interpreted as an altruistic pursuit. Neither of these can capture a wide range of mainstream adopters. In order for people to see meaning in sustainability, 'they must see some degree of personal benefit, regardless of their orientation in the World of Sustainability' (Stokes et al., 2014; The Hartman Group, 2013a).

Meaning - Concerns have been raised about how sustainable consumption is often misinterpreted and reduced to 'green consumerism' (Akenji, 2014; de Burgh-Woodman and King, 2013). Although awareness of sustainability as a concept is growing society-wide, there is still generalised confusion among the public about what sustainable practices and options really are - beyond products clearly labelled as 'green' or 'eco' (Hanss and Böhm, 2012). Also, sustainable lifestyles do not appear to be a very popular concept so far because they are often equated with 'settling for less' (Luchs et al., 2010). Ehrenfeld (2008) sees the fact that sustainability can be 'practiced' in manifold manifestations as an advantage, however he also points out that the lack of clearly defined meanings impacts on the significance it bears in people's lives.

Affinity - The consumerism discourse utilises highly developed strategies targeted to our senses and emotions. Conversely, sustainability discourses often lack connectedness and emotional appeal (Makower, 2013), over relying on scientific explanations and 'hard facts', assuming 'rational' decision-making and moral appeal. This approach is out-dated and new findings on human risk assessment and decision-making evidenced by behavioural economics show that perceptions, biases and emotions have a greater weight on our choices and preferences than facts (Kahneman, 2012). As Grimmer and Woolley (2012) recommend, 'sustainable offerings would benefit from a stronger appeal to the emotionality of customers to be more effective' (p.16). However, de Burgh-Woodman and King (2013) warn that we must be wary of counting on the emotionality or empathy generated by 'depletion and destruction scenarios' as motivators for lasting behaviour change, evidencing that 'humans enjoy a historically embedded relationship with nature in either its literal or metaphoric sense', which renders nature a passive constant that is 'just there' and hard to imagine it gone (ibid, p. 146).

Promise - Although sustainability's goal is to 'improve quality of life' - i.e. happiness and well-being - the sustainability discourse rarely acknowledges the emotional driving potential of this 'promise' for communicating with mainstream audiences. As universal, cross-cultural legitimate pursuits they are within the deepest and strongest intrinsic motivators that drive our aspirations and goals, and consequently our priorities and behaviours (Kasser et al., 2013). Their effectiveness as deep emotional drivers is demonstrated in the extent to which we have surrendered to the allure of consumerist illusions that reflect them (Kasser, 2002). Evidence suggests that emulating the commodity discourse (Connolly and Prothero, 2003) by representing sustainable offerings with references around personal benefits of 'greater happiness and well-being' (Sääksjärvi and Hellén, 2013) and establishing a positive emotional connection with users' sensibilities pose a better chance for their wider appeal and uptake.

Error! Reference source not found. summarises the extant arguments on why sustainable offerings are competing poorly against consumerist propositions. 


\begin{tabular}{|c|c|c|}
\hline & Consumerist Discourse & Sustainability Discourse \\
\hline Personal Benefits & Clear, direct & Unclear, indirect \\
\hline Meaning & Clear, targeted & Unclear, generic \\
\hline Affinity & Mainly emotional & $\begin{array}{c}\text { Personal happiness \& well-being } \\
\text { are underrepresented }\end{array}$ \\
\hline Promise & $\begin{array}{c}\text { Personal happiness \& well-being } \\
\text { are intentionally represented }\end{array}$ \\
\hline
\end{tabular}

Table 2 - Summarised comparison of the 'consumerism' and 'sustainability' lifestyle proposition discourses

To conclude, as humanity inevitably pushes forth for legitimate betterment, the concept of 'reduced consumption' (associated with current framings of sustainability) is perceived as regression, not progression in terms quality of life. As such, sustainable lifestyles do not appear to be a very popular concept because they are often equated with 'settling for less' (Luchs et al., 2010). On the other hand, sustainable development is defined as 'a way to achieve a better life for all humanity' (IUCN et al., 1991), therefore sustainability should be equated in people's minds as 'going for the best'.

The way in which the sustainability goals are 'translated' into offerings seems flawed; therefore the discursive gap between the intended and the perceived meaning needs to be addressed. The symbols - cultural references or codes employed to represent sustainable propositions need to reflect the intended meaning, and not the opposite.

\subsection{Implications for design in re-framing sustainable offerings}

As previously discussed, cultural codes and meanings are recalled upon to represent the utility and benefit, but also the values and identity of designed artefacts. These associations help to 'frame' and 'position' goods and services into categories making them 'visible' and, hopefully, desirable to the user (du Gay et al., 2013). Designers create these associations by appropriating and manipulating cultural codes already present - and often dominant - in the artefact's category discourses, and more often than not, in the designer's own cultural circle (Julier, 2006). The identification and selection of these codes seems to be mostly intuitive rather than intentional - due to a lack of appropriate processes and tools (Kazmierczak, 2003; Vezzoli et al., 2015) for strategic code mapping and selection.

In general terms, sustainable offerings are often framed around the aesthetics and narratives associated with the 'green/eco' category. This framing triggers associations that users have previously stored in their minds. This poses two main problems:

1. When the associations are positive, users who 'get' these meanings would be drawn and perhaps consider the proposition further.

2. If the associations are negative, or absent, the proposition becomes 'invisible' and will be consequently ignored as if non-existent, with only status quo choices being considered;

Positioning sustainable offering within the green/eco category, therefore, creates a closed loop of 'preaching to the converted' - i.e. only those already within the sustainability 'universe of meaning' connect with the proposition, and those outside of it remain unaffected (Grimmer and Woolley, 2012).

The need therefore arises to steer away from 'green/eco' codes and embrace new meanings that appeal to the many, and not the few (Santamaria, Escobar-Tello and Ross, 2015), so that sustainable innovations can stand as symbols of exciting new ways of belonging and being. As Lakoff (2010) rightly asserts 'Truth must be framed effectively to be seen at all. That is why an understanding of framing matters'. Therefore, working more strategically, rather than intuitively with cultural codes provides an opportunity for design to disrupt cultural misconceptions and revalorise the appeal of sustainable offerings. Sustainability can be 'reframed' through design representation by using favourable codes to ensure the perceived meaning corresponds with the intended meaning.

\section{Sustainable Product-Service Systems as an opportunity for radical disruption}

Considering the potential that semiotic methods offer to support design in the strategic construction of symbolic value, we propose an initial theory and methodological framework for their incorporation in the design process. The concepts are explored in the context of sustainable product-service systems (sustainable PSS), considering the cultural barriers they face for mainstream diffusion and uptake.

As discussed in earlier sections, to successfully compete against existing options, sustainable innovations need to satisfy the socio-psychological as well as the utilitarian aspect of consumption (Ceschin, et al., 2014), and clearly demonstrate how they can benefit people's lives (Stokes et al., 2014) in ways that current offers do not. Strategies are 
required for designing product renting, sharing and pooling systems (these pose the greatest environmental benefit) that deliver high symbolic value, while sacrifices with regards to tangible value are minimized (Tukker, 2004).

In a sustainable PSS innovation, symbolic value can be constructed through a coherent 'system aesthetic,' i.e. an integrated perception of the products, communication, services and interactions and practices embedded in the PSS (Ceschin et al., 2014). But these aspects should be informed by a deep understanding of the user's socio-cultural context (Light and Miskelly, 2014; Wong, 2004). As Norman and Verganti (2014) suggest 'radical innovations can be designdriven through a better understanding of potential patterns of meanings. These can emerge through research and observations rooted in more general socio-cultural changes, as an understanding of how society and culture are changing' (p. 95, italics added).

In summary, studying and mapping socio-cultural meaning associations at macro (global) level, and micro (local/contextual) level is key to strategically insert radical innovations in the market.

\subsection{Initial theoretical proposition}

We propose that semiotic and cultural analysis research is implemented early in the design process to obtain insights that can help in rooting the sustainable PSS innovation in context and, by strategically incorporating the most favourable codes, enhance its relevance and desirability. Figure 4 exemplifies this process as incorporated into to the widely adopted Double Diamond model design process (Design Council, 2005). In sustainable PSS, the form of the items, the branding and communications and the experience of the service all interfere with each other in terms of how the innovation's value is perceived (Ceschin et al., 2014). Therefore, data on meaning networks, associations and aesthetic codes needs to be available to the designer from the outset in order to develop design innovations that are welcomed and valued in the context in which they will operate. But because these codes vary from culture to culture - and even within a product/service category - a deep understanding of contextual signifiers is key to developing sustainable PSS that can succeed in the culture where they will operate.

As the intended meanings of the sustainable PSS will be negotiated by user interactions, further analysis needs to be carried out in order to improve the innovation and keep it relevant for the user, as illustrated in Figure 4.

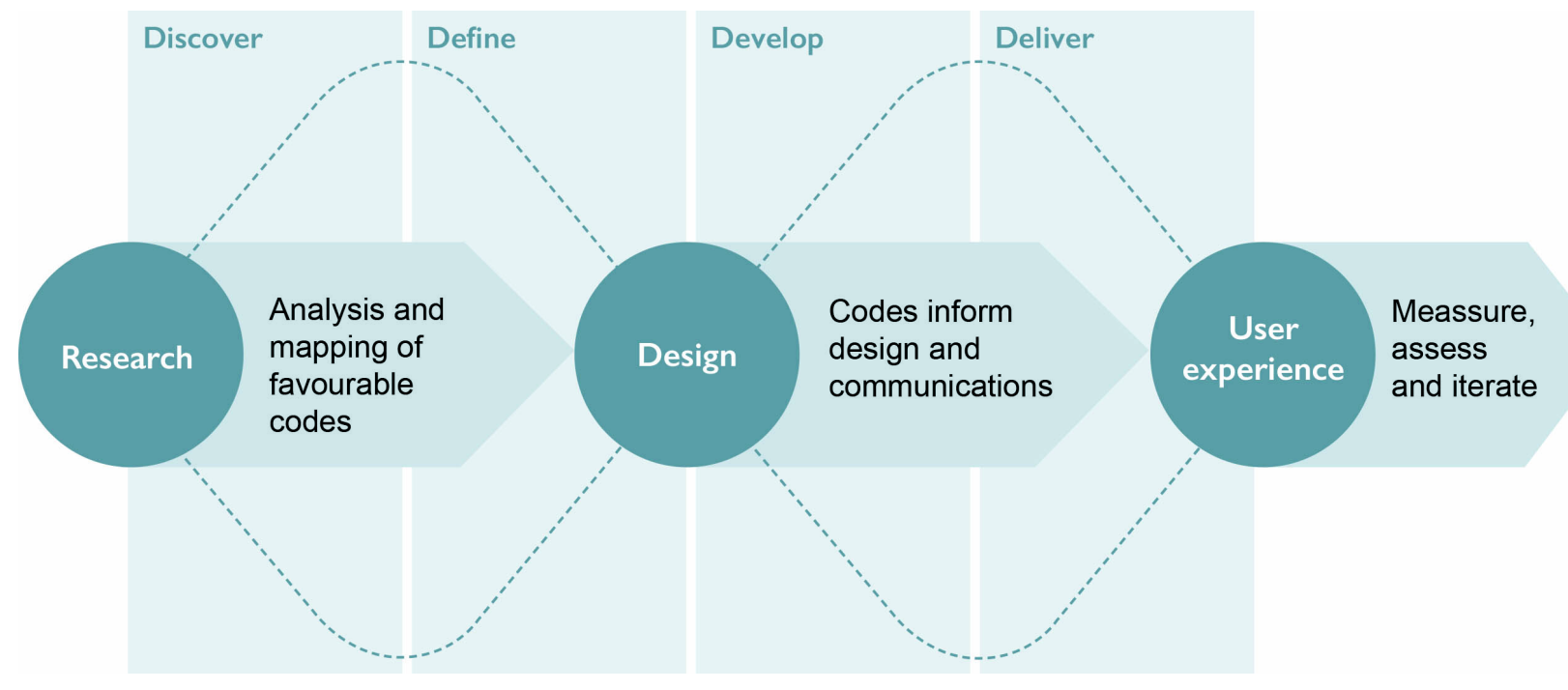

Figure 4 - Initial proposal for incorporating semiotic and cultural analysis research to the design process

At the research stage, (illustrated in Figure 4), we propose that mapping the most favourable codes is conducted at two levels:

1. A macro (global) level that deals with the semiotic aspects in terms of how these innovations are primarily promoted and understood at a global, cross-category level. This meaning is intrinsically linked to the wider intrinsic pursuit of wellbeing in a globalised culture - i.e. how relevant, in the eyes of the users, is the innovation to improve their quality of life?

2. A micro (local) level that deals with the aesthetic associations in terms of how the innovation is represented in the user's particular social context. This meaning is related to the sensibilities, identification and social aspects of consumption as lived experience - i.e. what symbolic value does the innovation offer to the user in a social context? What would its adoption 'say' about him/her?

The following sections explain these two levels in more detail. 


\subsubsection{Macro (global) meaning: how relevant do sustainable PSS innovations appear to the user?}

Widening adoption of sustainable lifestyles implies 'winning over' users who are currently not interested in, or ignore these practices. To extend the cultural resonance, and therefore diffusion of sustainable PSS, it is necessary to create associations that reside outside the niche 'sustainability universe' of meaning. But if the meaning is not to be constructed around this concept, what other (more favourable) meaning associations exist for them? And how can we tell which meanings will position sustainable PSS as of higher value than competing options?

Assuming that sustainable PSS innovations have been designed to reflect intrinsic values and benefits as well as environmental ones, these innovations can be driven by a meaning change informed by wide societal trends, for the example, the pursuit of a more dematerialised concept of well-being (Brown and Vergragt, 2015).

We suggest that:

Proposition 1. Sustainable products and services may have a higher chance of being more widely understood and adopted if framed around the well-being discourse rather than the environmental discourse. This means making the values and benefits of sustainable living (greater happiness and well-being) evidently obvious to their intended users.

Norman and Verganti (2014) state that 'meaning-driven innovation starts from the comprehension of subtle and unspoken dynamics in socio-cultural models and results in radically new meanings and languages - often implying a change in socio-cultural regimes' (Norman \& Verganti, 2014, p. 90). At this historical point, one of the most evident sociocultural changes is the rising interest in life satisfaction and well-being (Brown and Vergragt, 2015; The Hartman Group, 2013b). Since most people are concerned with their own (and their loved ones) well-being and life satisfaction, these universal, cross-cultural and positive intrinsic values present a strong platform of meaning upon which to build personal benefits for sustainable PSS.

Therefore, the generic proposition for sustainable PSS could be constructed around the meaning 'for greater wellbeing and life-satisfaction' by highlighting the aspects that enhance the lifestyle of the potential user. For example, LeTote.com service provides women with access to fashionable garments and jewellery. For a modest subscription fee, the users gain access to a wider range and number of items than they could potentially afford to buy. Here, the personal benefit is provided through access instead of ownership and the user's experience is personally enriched (a benefit that can potentially boost their subjective well-being) beyond the environmental benefit of reducing landfill waste.

It is evident that how these benefits are incorporated and prioritised in the proposition and narrative of the innovation is very much a matter of design.

\subsubsection{Micro (local) meaning: what symbolic value does innovation offer to the user in a social context?}

Even when a sustainable PSS has good inbuilt personal benefits, it is still quite possible that it will not be perceived as a desirable option for the user if it lacks the allure or symbolic value that other competing options provide. As identified in earlier sections, the main barrier for potential sustainable PSS users is the cultural shift necessary to value an ownerless way of having a satisfaction fulfilled, as opposed to owning a product (Goedkoop et al., 1999). Because products provide satisfaction also as symbols of status, identity and belonging (Hamilton, 2010; Crilly, 2008), for customers to value these options, sustainable PSS will need to carry symbolic features (or benefits) that satisfy the user's social, psychological and emotional needs. We suggest that:

Proposition 2. Sustainable offerings can be made more appealing and relevant to users by attributing valuable contextual meanings and cultural associations to them. This implies making available to designers the most favourable contextual cultural codes so that sustainable innovations are represented as superior to competing, non-sustainable alternatives.

Using the example described in the previous section,

postulates how different sustainable PSS benefits (or features, henceforth used interchangeably) might fare from the user's perception:

\begin{tabular}{|l|l|l|l|}
\hline Benefit/Feature & Example & $\begin{array}{l}\text { Perceptual } \\
\text { connection }\end{array}$ & $\begin{array}{l}\text { Emotional } \\
\text { distance }\end{array}$ \\
\hline Environmental & Cuts landfill waste & Bigger-than-self & Far \\
\hline Functional & Saves money & Relative & Closer \\
\hline Symbolic & I look good and fashionable & Intimate & Closest \\
\hline
\end{tabular}


While people may agree that it is important to 'cut landfill waste' (environmental benefit) they may not be prepared to commit to lifestyle changes that mean they should sacrifice 'looking good and fashionable' (symbolic benefit), even if it 'saves them money' (functional benefit). Conversely, they may be more willing to sacrifice functional benefits (such as 'saving money') in order to prioritise symbolic benefits ('looking good and fashionable'). The symbolic value is intimately related to the construction of our identity, and consequently carries a heavier weight against other features. This might explain why it feels 'sacrificial' when we prioritise other features over the symbolic ones. As the feeling of worth and identity is relegated, life satisfaction decreases and there is a feeling of losing out (Hamilton, 2010).

As symbolic features help us to construct identity in a socio-cultural context, in order to build symbolic features into sustainable PSS it is essential to understand the 'social rules' (codes) at play in that particular context. When sustainable PSS experiences are designed and represented using contextually relevant codes and high value signifiers, they 'feel' in tune with what is socially considered 'progressive' and 'aspirational' in their context. Then, the chances that these innovations will satisfy emotional, social and psychological needs of the user are considerably higher. For example, London's farmers' markets are perceived as enriching experiences where shoppers 'delight their senses' with carefully crafted, bespoke and authentic choices. This could be attributed to the great deal of effort producers invest into presenting themselves in the best possible light, crafting engaging personal stories, aesthetically pleasing stalls, consistent branding, uniforms and packaging.

\subsection{Proposed methodological framework for design}

Drawing on the theoretical propositions described in the previous section, the methods illustrated in Figures 1 and 2 , and the three stages outlined in Figure 4, we elaborate an Initial Methodological Framework for the integration of cultural code mapping into the design process, as illustrated in Figure 5.

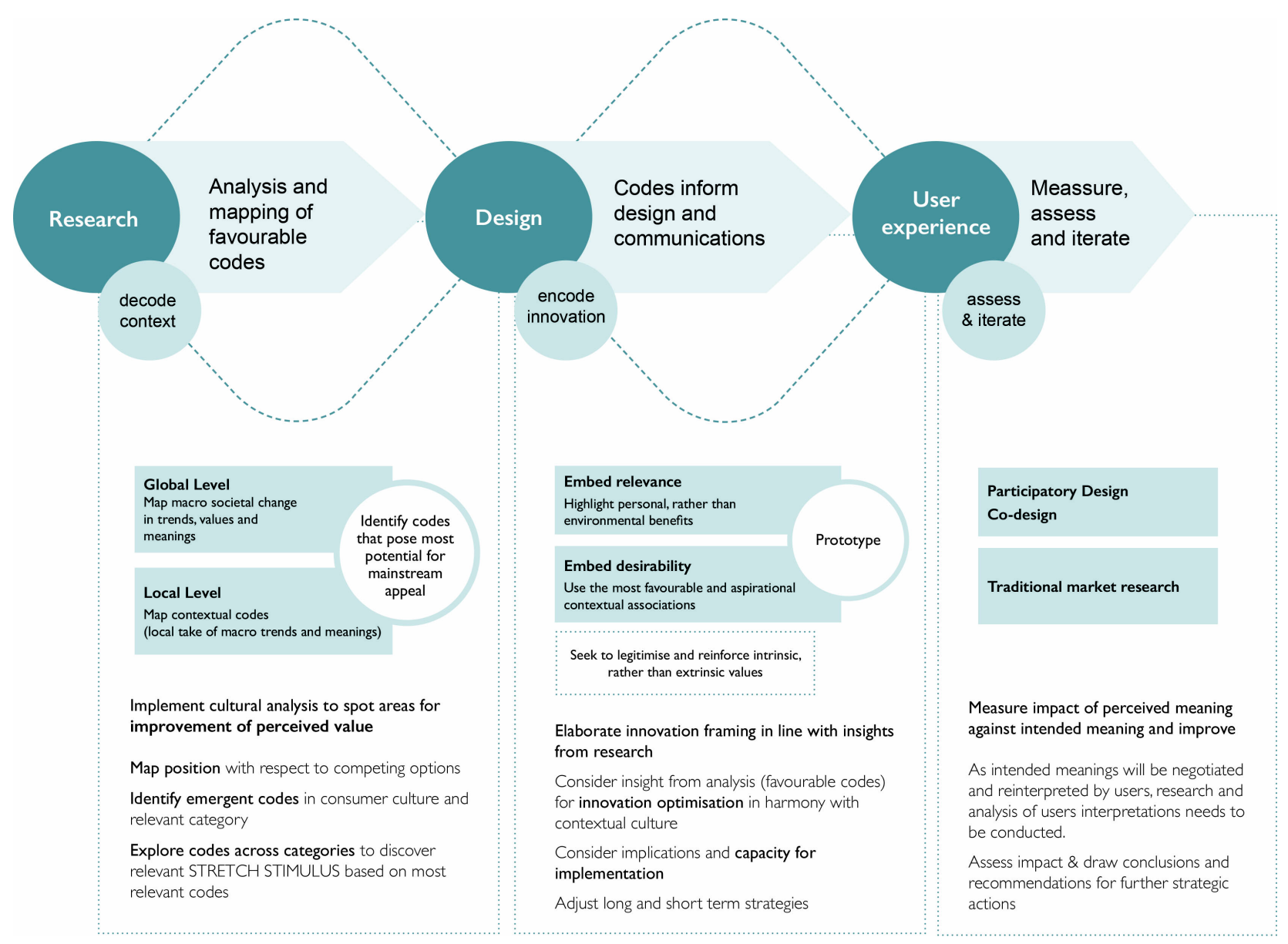

Figure 5 - Initial methodological framework for incorporating semiotic and cultural analysis into the design process.

This initial framework, which forms part of a larger research project, is being further developed and refined empirically through a series of participatory action research 'cycles' involving designers and existing sustainable PSS social 
enterprises. The outcomes are intended to empower design practitioners and design education with a more strategic approach to design, diffusion and communication of sustainable PSS.

\subsection{Theoretical premises}

In light of the above, this contribution highlights the relevance of implementing semiotic and cultural analysis methods for mapping and identifying favourable cultural codes, as a strategy to enhance the desirability, perceived value and appeal of sustainable PSS that contribute to sustainability and well-being.

Its premises are as follows:

1. Sustainable PSS need to be developed and promoted in a culturally relevant way, where contextual symbolic aspects of consumption are taken into account. In order to maximise user deep satisfaction they must be developed to satisfy socio-psychological as well as utilitarian and practical needs of the user, hence incorporating added value for the user in the creation of identity (symbolic features), especially those associated with subjective well-being and happiness,.

2. The designer's role is extended to encompass a more conscious understanding of the cultural mediation role involved in design practice, which now requires not only dealing with the concept generation and development of the innovation itself, but also with the cultural associations, values and meanings that the innovation bears into the cultural context of users.

3. It is proposed that designers are to extend the concern of their practice beyond the formulation of concept and into the diffusion and promotion of these innovations. For that, designers will need to familiarise themselves with tools and methods used in communication practices, as well as consumption practice theory and cultural analysis. Extending the role of the designer to this field of action implies that their scope will require a greater involvement in the developing the propositions - be it brand elements, processes, actors' roles - and requires them to be able to understand and work with cognitive aspects such as aesthetic and semiotic codes, narrative frames and values.

4. If designers are to develop culturally relevant 'value symbols' it is essential that they have access to data on the aesthetic and semiotic codes associated with high value, desirability and legitimacy in the cultural context of the user. This data will positively impact the design concept and its diffusion enhancing its perceived value by making it more desirable, but also to extend its purpose into changing lifestyles by establishing new habits and cultural value associations.

\section{Conclusions}

In order to turn the tide of the consumerist paradigm and transition society towards more sustainable lifestyles, a reframing of the concept of sustainability in culture needs to take place. In this, designers as cultural intermediaries can and should play a key role.

Building on valuable cultural references and positive associations already present in the cultural context of the user, designers can accelerate the introduction of more sustainable processes and practices and help create new associations of value. This research aims to further enable designers with an initial methodological framework for mapping the cultural landscape and identifying the most favourable codes in the context where the innovation will operate. These methods will aid designers in creating more meaningful and enriching sustainable Product Service System experiences that, while still being 'good for the environment' they also promote and legitimise the intrinsic values that underpin people's happiness and well-being and satisfy user's utilitarian and socio-psychological needs.

Furthermore, looking at the perception and value of sustainability's meaning in culture opens a new area of Design for Sustainability research, posing important opportunities to have a higher impact in society. But it also requires the elaboration of new theories, methods and skills to empower design to operate as an agent of change towards this systemic cultural transition.

In proposing to incorporate semiotic and cultural analysis methods to the design process, we hope to open a field of enquiry for strategic sustainable design research, seeking to gain a deeper understanding of users in their socio-cultural environments.

\section{References}

Akenji, L., 2014. Consumer scapegoatism and limits to green consumerism. J. Clean. Prod. 63, 13e23. http://dx.doi.org/10.1016/j.jclepro.2013.05.022.

Barthes, R., 1967. Elements of Semiology (Annette Lavers and Colin Smith, Trans.). Jonathan Cape, London.

Baudrillard, J., 1988. In: Poster, Mark (Ed.), Selected Writings. Polity Press, Cambridge.

Belk, R., 2004. Are we what we own? In: Benson, A.L. (Ed.), I Shop, Therefore I Am: Compulsive Buying and the Search for Self. Rowman \& Littlefield, Maryland. 
Bourdieu, P., 2010. Distinction: a Social Critique of the Judgement of Taste. Routledge, Abingdon.

Brown, H.S., Vergragt, P.J., 2015. From consumerism to wellbeing: toward a cultural transition? J. Clean. Prod. http://dx.doi.org/10.1016/j.jclepro.2015.04.107.

Castells, M., 2013. Communication Power, 2013th ed. Oxford University Press, Oxford, UK.

Ceschin, F., Vezzoli, C., Zingale, S., 2014. An aesthetic for sustainable interactions in product-service systems?. In: ProductService System Design for Sustainability. Greenleaf Publishing, Sheffield.

Connolly, J., Prothero, A., 2003. Sustainable consumption: consumption, consumers and the commodity discourse. Consum. Mark. Cult. 6, 275e291. http:// dx.doi.org/10.1080/1025386032000168311.

Corner, A., Markowitz, E., Pidgeon, N., 2014. Public engagement with climate change: the role of human values. Wiley Interdiscip. Rev. Clim. Chang. 5 http:// dx.doi.org/10.1002/wcc.269.

Crilly, N., Good, D., Matravers, D., Clarkson, P.J., 2008. Design as communication: exploring the validity and utility of relating intention to interpretation. Des. Stud. 29, 425e457. http://dx.doi.org/10.1016/j.destud.2008.05.002.

De Burgh-Woodman, H., King, D., 2013. Sustainability and the human/nature connection: a critical discourse analysis of being 'symbolically' sustainable. Consum. Mark. Cult. 16, 145e168. http://dx.doi.org/10.1080/10253866. 2012.662834 .

Denzin, N.K., Lincoln, Y., 2003. Introduction: the discipline and practice of qualitative research. In: Denzin, N.K., Lincoln, Y. (Eds.), The Landscape of Qualitative Research. Sage, Thousand Oaks, CA, pp. $1 \mathrm{e} 46$.

Design Council, 2005. A Study of the Design Process. Design Council. http://www. designcouncil.org.uk/sites/default/files/asset/document/ElevenLessons_Design_Council\%20(2).pdf

Du Gay, P., Hall, S., Janes, L., Madsen, A., Mackay, H., Negus, K., 2013. Doing Cultural Studies: the Story of the Sony Walkman, second ed. SAGE, London.

Ehrenfeld, J., 2008. Sustainability by Design: a Subversive Strategy for Transforming Our Consumer Culture. Yale University Press.

Ehrenfeld, J., 2013. Flourishing: A Frank Conversation About Sustainability. Greenleaf Publishing.

Evans, M., 2014. Advanced Semiotics: Apply Theory to Business Decisions Faced by Management (Training Course). Market Research Society, London. http://www. mrs.org.uk/event/course/331/id/8505.

Evans, M., Shivakumar, H., 2010. Insight, Cultural Diversity, Revolutionary Change: Joined up Semiotic Thinking for Developing Markets. ESOMAR.

Fuad-Luke, A., 2009. Design Activism: Beautiful Strangeness for a Sustainable World. Earthscan, London.

Gilbert-Jones, R., 2013. Should Supply or Demand Drive Sustainable Products? [WWW Document]. Greenbiz.com. URL. http://www.greenbiz.com/blog/2013/07/04/should-supply-or-demand-drive-sustainable-products (accessed 29.06.15.).

Goedkoop, M.J., Van Halen, C.J.G., Te Riele, H.R.M., Rommens, P.J.M., 1999. Product service systems, ecological and economic basics. Econ. Aff. 36, 132. http:// dx.doi.org/10.1111/j.1365-294X.2004.02125.x.

Grimmer, M., Woolley, M., 2012. Green marketing messages and consumers' purchase intentions: promoting personal versus environmental benefits. J. Mark. Commun. 1e20. http://dx.doi.org/10.1080/13527266.2012.684065.

Grouzet, F.M.E., Kasser, T., Ahuvia, A., Dols, J.M.F., Kim, Y., Lau, S., Ryan, R.M., Saunders, S., Schmuck, P., Sheldon, K.M., 2005. The structure of goal contents across 15 cultures. J. Pers. Soc. Psychol. 89, 800e816. http://dx.doi.org/10.1037/ 00223514.89.5.800.

Hamilton, C., 2010. Consumerism, self-creation and prospects for a new ecological consciousness. J. Clean. Prod. 18, 571e575. http://dx.doi.org/10.1016/j.jclepro. 2009.09.013.

Hanss, D., Böhm, G., 2012. Sustainability seen from the perspective of consumers. Int. J. Consum. Stud. 36, $678 \mathrm{e} 687$. http://dx.doi.org/10.1111/j.1470-6431.2011.01045.x.

Harvey, M., Evans, M., 2001. Decoding competitive propositions: a semiotic alternative to traditional advertising research. Int. J. Mark. Res. 43, 171e187.

Henare, A., Holbraad, M., Wastell, S., 2007. Thinking through Things: Theorising Artefacts Ethnographically. Routledge, Abingdon. 
Hodge, R., Kress, G., 1988. Social Semiotics, first ed. Polity Press, Cambridge.

IUCN, UNEP, WWF, 1991. Caring for the Earth: a Strategy for Sustainable Living. International Union for the Conservation of Nature and Natural Resources.

Jackson, T., Victor, P.A., 2013. Green Economy at Community Scale. http:// metcalffoundation.com/publicationsresources/view/green-economy/.

Julier, G., 2006. From visual culture to design culture. Des. Issues 22. http:// dx.doi.org/10.1162/074793606775247817.

Julier, G., 2013. The Culture of Design. SAGE Publications Ltd.

Kahneman, D., 2012. Thinking, Fast and Slow. Penguin UK, London.

Kahneman, D., Krueger, A.B., 2006. Developments in the measurement of subjective well-being. J. Econ. Perspect. 20 , 3e24. http://dx.doi.org/10.1257/ 089533006776526030.

Karp, D.G., 1996. Values and their effect on pro-environmental behavior. Environ. Behav. 28, 111e133. http://dx.doi.org/10.1177/0013916596281006.

Kasser, T., 2002. The High Price of Materialism. MIT Press.

Kasser, T., Rosenblum, K.L., Sameroff, A.J., Deci, E.L., Niemiec, C.P., Ryan, R.M., Arnad? ? ottir, O., Bond, R., Dittmar, H., Dungan, N., Hawks, S., 2013. Changes in materialism, changes in psychological well-being: evidence from three longitudinal studies and an intervention experiment. Motiv. Emot. 1e22. http:// dx.doi.org/10.1007/s11031-013-9371-4.

Kazmierczak, E.T., 2003. Design as meaning making: from making things to the design of thinking. Des. Issues $19,45 \mathrm{e} 59$. http://dx.doi.org/10.1162/0747936037 65201406.

Kollmuss, A., Agyeman, J., 2002. Mind the gap: why do people act environmentally and what are the barriers to proenvironmental behavior? Environ. Educ. Res. 8, 239e260. http://dx.doi.org/10.1080/13504620220145401.

Lakoff, G., 2010.Why it matters how we frame the environment. Environ. Commun. J. Nat. Cult. 4, 70e81. http://dx.doi.org/10.1080/17524030903529749.

Layard, R., 2011. Happiness: Lessons from a New Science, second ed. Penguin UK.

Lebow, V., 1955. Price competition in 1955. J. Retail (spring) 5e14. http://ablemesh. co.uk/PDFs/journal-ofretailing1955.pdf.

Light, A., Miskelly, C., 2014. Design for Sharing. http://www.fccrnet.org/wp-content/ uploads/2014/11/design-forsharing-webversion.pdf.

Luchs, M.G., Naylor, R.W., Irwin, J.R., Raghunathan, R., 2010. The sustainability liability: potential negative effects of ethicality on product preference. J. Mark. 74, 18e31. http://dx.doi.org/10.1509/jmkg.74.5.18.

Maggio-Muller, K., Evans, M., 2008. Culture, communications and business e the power of advanced semiotics. Int. J. Mark. Res. Mark. Res. Soc. 169e180.

Maguire, J.S., Matthews, J., 2012. Are we all cultural intermediaries now? An introduction to cultural intermediaries in context. Eur. J. Cult. Stud.15, 551e562. http://dx.doi.org/10.1177/1367549412445762.

Makower, J., 2013. 5 Reasons Green Marketing Is Going Nowhere. LinkedIn. https:// www.linkedin.com/today/post/article/20130312180239-127714-5-reasons- green-marketing-is-goingnowhere?trk $1 / 4 \mathrm{mp}$-reader-card.

Mandoki, K., 2007. Everyday Aesthetics: Prosaics, the Play of Culture and Social Identities, Philosophy and Literature. Ashgate Publishing, Ltd.

Manzini, E., 1999. Strategic design for sustainability: towards a new mix of products and services. In: Proceedings First International Symposium on Environmentally Conscious Design and Inverse Manufacturing. IEEE, pp. 434e437. http:// dx.doi.org/10.1109/ECODIM.1999.747651.

Manzini, E., 2014. Making things happen: social innovation and design. Des. Issues 30, 57e66. http://dx.doi.org/10.1162/DESI.

Manzini, E., Vezzoli, C., 2003. A strategic design approach to develop sustainable product service systems: examples taken from the "environmentally friendly innovation" Italian prize. J. Clean. Prod. 11, 851e857. http://dx.doi.org/10.1016/ S0959-6526(02)00153-1. 
Markussen, T., 2013. The disruptive aesthetics of design activism: enacting design between art and politics. Des. Issues 29, 38e50. http://dx.doi.org/10.1162/DESI_a_00195.

McKenzie-Mohr, D., 2013. Fostering Sustainable Behavior: an Introduction to Community-based Social Marketing, third ed. New Society Publishers.

Melles, G., de Vere, I., Misic, V., 2011. Socially responsible design: thinking beyond the triple bottom line to socially responsive and sustainable product design. CoDesign 7, 143e154. http://dx.doi.org/10.1080/15710882.2011.630473.

Mont, O., Plepys, A., 2008. Sustainable consumption progress: should we be proud or alarmed? J. Clean. Prod. 16, 531 e537. http://dx.doi.org/10.1016/ j.jclepro.2007.01.009.

Mont, O., Neuvonen, A., Lähteenoja, S., 2014. Sustainable lifestyles 2050: stake- holder visions, emerging practices and future research. J. Clean. Prod. 63, 24e32. http://dx.doi.org/10.1016/j.jclepro.2013.09.007.

Mylan, J., 2014. Understanding the diffusion of sustainable product-service systems: insights from the sociology of consumption and practice theory. J. Clean. Prod. 97, 13e20. http://dx.doi.org/10.1016/j.jclepro.2014.01.065.

Negus, K., 2002. The work of cultural intermediaries and the enduring distance between production and consumption. Cult. Stud. 16 (4), 501e515. http:// dx.doi.org/10.1080/09502380210139089.

Nelson, A., 2008. Steering Sustainability in an Urbanising World. Ashgate Publishing, Ltd., Abingdon.

Norman, D.A., Verganti, R., 2014. Incremental and radical innovation: design research vs. technology and meaning change, 30. http://dx.doi.org/10.1162/ DESI.

Nöth, W., 1990. Handbook of Semiotics. Indiana University Press, Bloomington, IN.

Oswald, L.R., Mick, D., 2006. The semiotic paradigm on meaning in the marketplace. In: Belk, R.W. (Ed.), Handbook of Qualitative Research Methods in Marketing. Edward Elgar Publishing Ltd., Northampton, MA.

Oswald, L.R., 2012. Marketing Semiotics: Signs, Strategies, and Brand Value. Oxford University Press, Oxford, UK.

Oswald, L.R., 2015. Creating Value: the Theory and Practice of Marketing Semiotics Research. Oxford University Press, Oxford, UK.

Papanek, V., 1985. Design for the Real World: Human Ecology and Social Change, second ed. Thames \& Hudson.

Rapaille, C., 2007. The Culture Code: an Ingenious Way to Understand Why People Around the World Live and Buy as They Do. Broadway Books, New York.

Rexfelt, O., Ornäs, V.H., 2009. Consumer acceptance of product-service systems: designing for relative advantages and uncertainty reductions. J. Manuf. Technol. Manag. 20, 674e699. http://dx.doi.org/10.1108/174103809 10961055.

Sääksjärvi, M., Hellén, K., 2013. How designers and marketers can work together to support consumers' happiness. Int. J. Des. 7, 33e44.

Santamaria, L., Escobar-Tello, M.C., Ross, T., 2015. Planet or people? Redefining the ideological position of sustainable design. In: The Value of Design Research. EAD (European Association of Design), Paris. http://dx.doi.org/10.13140/ RG.2.1.2327.9527.

Schmuck, P., Kasser, T., Ryan, R.M., 1999. Intrinsic and Extrinsic Goals: Their Structure and Relationship to Well-Being in German and U.S. College Students, pp. 225e241.

Schwartz, S.H., Cieciuch, J., Vecchione, M., Davidov, E., Fischer, R., Beierlein, C., Ramos, A., Verkasalo, M., Lönnqvist, J.-E., Demirutku, K., Dirilen-Gumus, O., Konty, M., 2012. Refining the theory of basic individual values. J. Pers. Soc. Psychol. 103, 663 e688.

Shaw, D., Grehan, E., Shiu, E.M.K., 2004. An exploration of values in ethical consumer decision making, 4, $185 \mathrm{e} 200$. http://dx.doi.org/10.1002/cb.3.

Shove, E., Watson, M., Hand, M., Ingram, J., 2007. The Design of Everyday Life. Berg, Oxford, UK.

Slater, D., 1999. Consumer Culture and Modernity, 1st ed. Polity Press.

Sterman, J., 2012. Sustaining sustainability: creating a systems science in a fragmented academy and polarized world. In: Weinstein, M., Turner, R.E. (Eds.), Sustainability Science: the Emerging Paradigm and the Urban Environment. Springer, pp. 21e58. http://jsterman.scripts.mit.edu/On-Line_Publications. html\#2011sustaining. 
Stokes, K., Clarence, E., Anderson, L., Rinne, A., 2014. Making Sense of the UK Collaborative Economy. London. http://www.nesta.org.uk/publications/making- sense-uk-collaborative-economy.

The Hartman Group, 2013a. Sustainability 2013. From: http://www.hartman-group. com/publications/reports/sustainability-2013.

The Hartman Group, 2013b. Health + Wellness: a Culture of Wellness. From: http:// www.hartmangroup.com/download/report/health-wellness-a-culture-of- wellness-2013.

Tukker, A., 2004. Eight types of product-service system: eight ways to sustainability? Experiences from SusProNet. Bus. Strateg. Environ. 13, 246e260. http:// dx.doi.org/10.1002/bse.414.

Tversky, A., Kahneman, D., 1981. The framing of decisions and the psychology of choice. Science (80-) 211, $453 \mathrm{e} 458$. http://dx.doi.org/10.1126/science.7455683.

Verganti, R., 2008. Design, meanings, and radical innovation: a metamodel and a research agenda. J. Prod. Innov. Manag. 25, 436e456. http://dx.doi.org/10.1111/ j.1540-5885.2008.00313.x.

Vergragt, P., Akenji, L., Dewick, P., 2014. Sustainable production, consumption, and livelihoods: global and regional research perspectives. J. Clean. Prod. 63, 1e12. http://dx.doi.org/10.1016/j.jclepro.2013.09.028.

Vezzoli, C., Kohtala, C., Srinivasan, A., 2014. Product-Service System Design for Sustainability. Greenleaf, Sheffield.

Vezzoli, C., Ceschin, F., Diehl, J.C., Kohtala, C., 2015. New design challenges to widely implement "sustainable productservice systems”. J. Clean. Prod. 97, 1e12. http://dx.doi.org/10.1016/j.jclepro.2015.02.061.

Wilkinson, R., Pickett, K., 2009. The Spirit Level: Why Equality Is Better for Everyone. Penguin UK, London.

Williams, R., 1977. Marxism and Literature, Reprinted. Oxford University Press, Ox- ford, UK.

Wong, M.T.N., 2004. Implementation of Innovative Product Service Systems in the Consumer Goods Industry (PhD dissertation). Cambridge University. 